\title{
Shape Optimization to Reduce Wind Pressure on the Surfaces of a Rectangular Building with Horizontal Limbs
}

\author{
Rajdip Paul ${ }^{* 1}$, Sujit Kumar Dalui ${ }^{1}$ \\ ${ }^{1}$ Civil Engineering Department, Indian Institute of Engineering Science and Technology, Shibpur, P.O.- Botanic Garden, Shalimar, West \\ Bengal-711103, Howrah, India \\ * Corresponding author, e-mail: rajdippaul.rs2014@civil.iiests.ac.in
}

Received: 20 July 2020, Accepted: 07 September 2020, Published online: 16 October 2020

\begin{abstract}
The present study consists of shape optimization of a rectangular plan shaped tall building with horizontal limbs under wind attack, which would minimize the wind pressure on all the faces of the building model simultaneously. For the purpose, the external pressure coefficients on different faces of the building $\left(C_{p e}\right)$ are selected as the objective functions. The position of the limbs and the wind incidence angle are taken as design variables. The design of experiment (DOE) is done using random sampling. The values of the objective functions are obtained by using Computational Fluid Dynamics method of simulated wind flow at each design point. The building model has a constant plan area $22500 \mathrm{~mm}^{2}$. The length and velocity scales are taken as 1:300 and 1:5, respectively. The results are used to construct the surrogate models of the objective functions using Response Surface Approximation method. The optimization study is done using the Multi-Objective Genetic Algorithm. The building shapes corresponding to the Pareto optimal decision variables are shown. The function values corresponding to the decision variables are verified by further introducing a CFD study.
\end{abstract}

Keywords

tall building, wind pressure coefficient, optimization, multi-objective genetic algorithm, pareto-optimal solutions, Response Surface Approximation

\section{Introduction}

Due to the associated intricacy during wind-structure interaction in case of tall flexible buildings, simple quasi-static method of analysis is insufficient. Physical modelling using a wind tunnel or numerical simulation technique is the recommended means of obtaining precise information on wind effects on tall buildings $[1,2]$. Numerical simulation can be carried out using computational fluid dynamics (CFD) under simulated atmospheric boundary layer (ABL). For super tall buildings, the wind is the predominant lateral load. There arises many flow situations and dynamic responses when wind interacts with tall buildings.

Moreover, if the tall building is built with unconventional shapes or in unusual locations, then wind becomes a phenomenon of high complexity concerning the design of tall buildings against the wind. The dynamic characteristics of wind depend on many factors, including the outer shape of a building. Hence wind loads on structural frames are calculated based on the elastic response of the whole building against fluctuating wind forces. Globally the building codes do not incorporate the expected maximum wind speed for the life of the building. Neither the wind standards consider the high local suction, which causes the first damage. So, model analysis of buildings is required to get a more in-depth insight into the wind-structure phenomenon. At present, wind tunnel experiment and numerical simulation using computational fluid dynamics (CFD) are the available research tools to carry out model analysis of tall buildings.

Researchers in the area of wind engineering have carried out studies on wind characteristics on tall structures using both experimental and numerical methods over the years. Kareem [3] illustrated the facts of the interference and proximity effects on the dynamic response of prismatic bluff bodies. Liang et al. [4] suggested empirical formulae for different wind tempted dynamic torsional responses through an analytical model. Lin et al. [5] conferred the results of an extensive wind-tunnel study on local wind forces on isolated tall buildings based on the experimental outcome of nine square and rectangular models [1:500]. Gomes et al. [6] enumerated experimental outcomes of 
L \& U shaped models with 1:100 length scale. Lam and Zhao [7] investigated in detail the effects of wind flow around a row of three square-plan tall buildings closely arranged in a row at wind angle $\theta=30^{\circ}$. The computational domain was discretized into finite volumes. Irwin [8] studied several bluff body aerodynamic phenomena and their effect on structural safety and occupant comfort. Zhang and $\mathrm{Gu}$ [9] connected the numerical simulation, and experimental research of wind encouraged interference effects. Fu et al. [10] computed field measurements of the characteristics of the boundary layer and storm reaction of two super tall buildings. Tse et al. [11] deliberated the general concept to find out the wind loadings and wind-induced responses of square tall buildings with different sizes of chamfered and recessed corners. Irwin [12] focused on the subject of determining and controlling the structural response under wind action for super-tall buildings which require much more pragmatically modelled wind engineering. Tominaga and Stathopoulos [13] modelled turbulent scalar flux in Computational Fluid Dynamics for near-field dispersion around buildings. Muehleisen and Patrizi [14] established parametric equations to get the values of pressure coefficients $\left[C_{p e}\right]$ on the surfaces of rectangular low-rise building models from experimental wind tunnel data. Amin and Ahuja [15] examined through wind tunnel studies on rectangular building models of different side ratios ranging from 0.25 to 4 . Kushal et al. [16] documented that the plan shape of a building has a great impact on the wind pressure. Verma et al. [17] discussed the effects of wind occurrence angle on wind pressure distribution on square plan tall buildings. Chakraborty et al. [18, 19] presented results of a combined wind tunnel and numerical study on the ' + ' plan shaped tall building for $0^{\circ}$ and $45^{\circ}$ wind incidence angles. Kheyari and Dalui [20] discussed the results of a case study to assess the wind load on a tall building under interference effects. Paul and Dalui [21] conferred the numerical results of a case study to understand the wind effects on the $\mathrm{Z}$ plan shaped tall building. Kumar and Dalui [22] compared the variation of mean pressure coefficients and force coefficients of regular cross plan shaped building with an angular cross plan shaped building for various wind incidence angles. Sanyal and Dalui [23] illustrated the variation of pressure due to the presence of the courtyard and the opening of a rectangular plan shaped building using a numerical technique. Bhattacharyya and Dalui [24] presented the mean pressure distribution on various walls of E plan shaped tall building through experimental and analytical studies for a widespread wind occurrence angle.
In modern days, rectangular buildings with horizontal limbs (Z-shape, E-shape, + shape) are becoming popular [21, 24, 18, 19]. For limbed buildings, numerous phenomena are contributing to dynamic responses under wind like buffeting, vortex shedding, galloping and flutter. Elshaer et al. [25] conferred that wind-induced loads and motions usually govern the properties and dimensions of the elements of the lateral load resisting systems in tall buildings. Therefore, a suitable configuration is essential to minimize the external surface pressure on different faces of a limbed building. The minimization may suitably be carried out by aerodynamic shape optimization studies using corner as well as architectural modifications. Over the years, researchers presented various optimization techniques in the field of civil engineering. Kaveh and Abdietehrani [26] adopted a genetic algorithm optimization technique for the discrete-sizing optimal design of frame structures employing force method for the analysis. Okasha and Frangopol [27] used genetic algorithms for multi-objective optimization of structural maintenance considering system reliability, redundancy and life-cycle cost. Kaveh and Shahrouzi [28] presented an expanding genetic population using minimal initial population for more efficient genetic search in structural problems. Kaveh et al. [29] used a non-dominated sorting genetic algorithm (NSGA-II) to develop a multi-objective approach for the optimal design of reinforced concrete cantilever retaining walls. The authors considered the economic cost and reinforcing bar congestion as the objective functions for minimization [29]. Jalili et al. [30] developed a Chaotic Biogeography-Based Optimization (CBBO) algorithm combining the chaos theory and the biogeography-based optimization (BBO) to achieve an efficient optimization method. This algorithm is suitable to avoid local optima and reduce premature convergence in the size and shape optimization of truss structures with natural frequency constraints [30]. Ezhilsabareesh et al. [31] adopted a CFD technique to simulate a bidirectional impulse turbine used in a wave energy device. Consequently, they performed a shape optimization using multiple surrogate models multi-objective evolutionary algorithm [31]. Jeong and Kim [32] optimized a fluidic oscillator using a multi-objective genetic algorithm with surrogate modelling. The study implemented the three-dimensional unsteady RANS analysis to enhance peak jet velocity at the outlet and simultaneously reduce pressure drop [32]. Xie [33] provided a guideline for building aerodynamic optimizations by assessing the effects of 
tapering, twisting and set-back in the reduction of wind response. Elshaer et al. [25] introduced an optimization framework coupled with the optimization algorithm, the computational fluid dynamics (CFD) solver, and the neural network model in an automated procedure to reduce the drag force acting on a tall building by changing the shape of its corners [25]. Elshaer et al. [34] applied the same aerodynamic optimization procedure (AOP) later to reliably predict the optimal building shape and improving the aerodynamic performance of tall buildings. The authors reduced the along-wind base moment by helical twisting and corner modifications of the building [34]. Daemei and Eghbali [35] investigated to reduce the length of the wake region of tall buildings through aerodynamic changes like rounded, chamfered and recessed corners.

The present study concentrates on optimizing the shape of a tall rectangular building with limbs by minimizing the wind pressure distribution on the various building facets. The building shape is chosen because it is a trendy shape in buildings like airports, hospitals, hostels, and academic blocks. The study adopts an aerodynamic optimization procedure (AOP) combining computational fluid dynamics (CFD), response surface approximation (RSA) and genetic algorithm (GA). After defining the design variables, a random sampling method is used to select 150 design points. Then CFD is adopted to conduct a numerical study using RANS k- $\varepsilon$ turbulence model. Mean pressure coefficient $\left(C_{p e}\right)$ on the different building faces of the parametric models are determined and utilized for the preparation of surrogate models using Response Surface Approximation (RSA) method. Finally, RSA models are used as surrogates to find the optimal building shapes using the genetic algorithm technique. The AOP is adopted to present Pareto-optimal solutions using the multi-objective genetic algorithm (MOGA). The main advantage of defining the Paretooptimal solutions is the flexibility to choose from a set of optimal building shapes satisfying multiple objectives rather than obtaining only one optimal shape in single-objective optimization. A separate CFD study is employed to check the function values as obtained from the MOGA study corresponding to the decision variables.

\section{Optimization procedure}

Fig. 1 illustrates the optimization procedure employed in the study. Design variables, design space, and objective functions are determined to define the optimization problem in the first step. In this study, mean pressure coefficients $\left(C_{p e}\right)$ on different building facets are considered as the objective

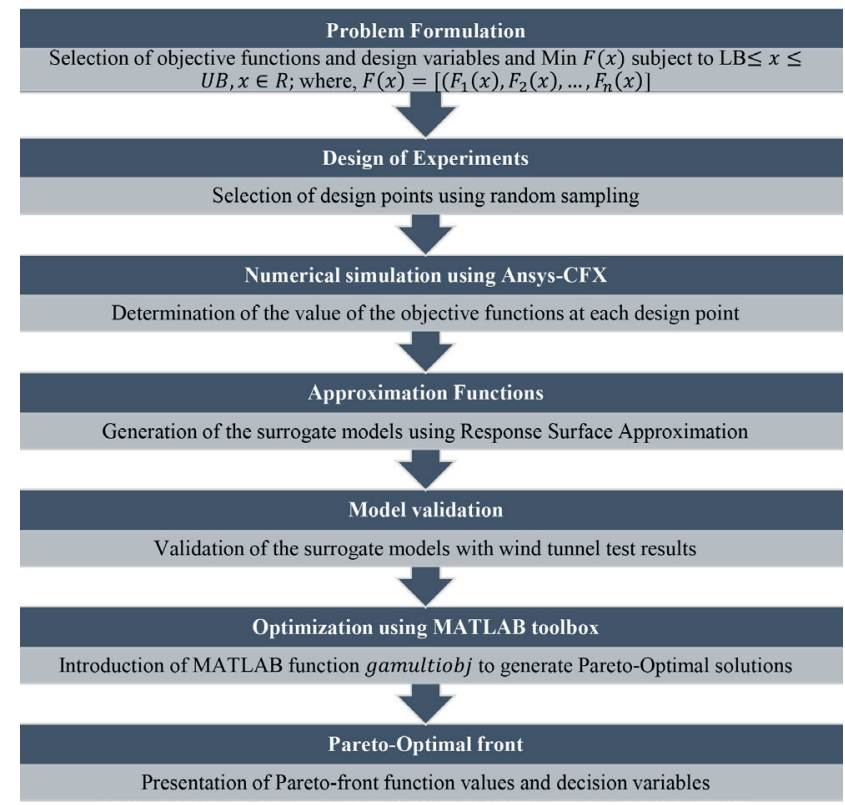

Fig. 1 Multi-objective optimization procedure

functions. A design-of-experiment (DOE) technique is used to select the design points in the design space. The values of the objective function are calculated based on unsteady CFD analysis at the design points. The results are used to construct response surface approximation (RSA) models of objective functions. The Pareto-optimal solutions are determined using the Multi-Objective Genetic Algorithm (MOGA). A set of Pareto-optimal solutions is assimilated by MOGA optimization algorithm. In the case of optimization problems having a single objective function, there is a global-optimal solution [36]. Whereas, for a multi-objective problem, the objectives being conflicting a single solution is barely the best for all the objective functions simultaneously. Hence instead of an optimal solution, there is a set of trade-off solutions, known as Pareto-optimal solutions or non-dominated solutions. These Pareto solutions are optimal in the sense that other solutions in the design space are not superior to them. In other words, all other solutions are dominated solutions that are inferior to the Pareto-optimal solutions [36]. The main advantage of defining the Pareto-optimal solutions is to achieve the flexibility to choose from a set of optimal building shapes satisfying multiple objectives rather than obtaining only one optimal shape in single-objective optimization [37].

\subsection{Response surface approximation methodology}

Response surface methodology (RSM) consists of an assembly of mathematical and statistical methods used for the development of a satisfactory functional relationship 
between a response of interest and the number of related control (or input) variables denoted by $x_{1}, x_{2}, \ldots, x_{k}$ [38]. Generally, such a correlation is unknown but can be estimated by a low-degree polynomial model of the form (Eq. (1))

$$
y=f^{\prime}(x) \beta+\epsilon,
$$

where $x=\left(x_{1}, x_{2}, \ldots, x_{k}\right)^{\prime}, f(x)$ is a vector function of $p$ elements comprising powers and cross- products of powers of $x_{1}, x_{2}, \ldots, x_{k}$ up to a certain degree represented by $d(\geq 1), \beta$ is a vector of $p$ unidentified constant coefficients called parameters. $\epsilon$ is a random experimental error assumed to have a zero mean. It is believed that model Eq. (1) can offer ample illustration of the response. In this case, the quantity $f^{\prime}(x) \beta$ represents the mean response, that is, the expected value of $y$, and is denoted by $\mu(x)$.

Two critical models are commonly used in RSM. These are exceptional cases of the model Eq. (1) and include the first-degree model $(d=1)$,

$y=\beta_{0}+\sum_{i=1}^{k} \beta_{i} x_{i}+\epsilon$.

And the second-degree model $(d=2)$,

$y=\beta_{0}+\sum_{i=1}^{k} \beta_{i} x_{i}+\sum \sum_{i<j} \beta_{i j} x_{i} x_{j}+\sum_{i=1}^{k} \beta_{i i} x_{i}^{2}+\epsilon$.

There is a threefold objective of considering a model such as Eq. (1).

1. To establish a relationship, although approximate, between $y$ and $x_{1}, x_{2}, \ldots, x_{k}$ that can be used to predict response values for given settings of the control variables.

2. To determine, through hypothesis testing, the significance of the factors whose levels are represented by $x_{1}, x_{2}, \ldots, x_{k}$.

3. To determine the optimum settings of $x_{1}, x_{2}, \ldots, x_{k}$ that results in the maximum (or minimum) response over a specific region of interest.

\subsection{Multi-objective genetic algorithm optimization}

The method of multi-objective optimization involves multiple objective functions. In mathematical relations, a multi-objective optimization problem can be expressed in Eq. (4) [39]:

$$
\begin{aligned}
& \min \left(f_{1}(x), f_{2}(x), \ldots, f_{k}(x)\right) \\
& \text { s.t. } x \in X .
\end{aligned}
$$

The number of objectives is always more than one, i.e., the integer $k \geq 2$ and set $X$ is the possible set of decision variables. Some constraint functions usually define the feasible set. Besides, the vector-valued objective function is generally defined as

$$
f: X \rightarrow \mathbb{R}^{k}, f(x)=\left(f_{1}(x), f_{2}(x), \ldots, f_{k}(x)\right)^{T} .
$$

If objective functions are to be maximized, it is equivalent to minimize their negatives. The image of $X$ is denoted by $\mathrm{Y} \in \mathbb{R}^{k}$. An element $x^{*} \in X$ is a feasible solution or a decision variable. A vector $\boldsymbol{z}=f\left(x^{*}\right) \in \mathbb{R}^{k}$ for a feasible solution $x^{*}$ is termed as an objective vector or an outcome. In multi-objective optimization, there does not exist a well-defined solution that minimizes all objective functions together. Mathematically, a feasible Pareto solution $x^{1} \in X$ is said to govern another solution $x^{2} \in X$, if

1. $f_{i}\left(x^{1}\right) \leq f_{i}\left(x^{2}\right)$ for all indices $i \in\{1,2, \ldots, k\}$ and

2. $f_{i}\left(x^{1}\right)<f_{i}\left(x^{2}\right)$ for at least one index $j \in\{1,2, \ldots, k\}$.

A solution $x^{*} \in X$ and the corresponding outcome $f\left(x^{*}\right)$ is termed as Pareto optimal if there is no another solution that governs it. The Pareto optimal solutions are also called the Pareto front, Pareto frontier, or Pareto boundary.

A Nadir objective vector bounds the Pareto front of a multi-objective optimization problem $z^{\text {nad }}$ and an ideal objective vector $z^{\text {ideal }}$, if these are finite. The Nadir objective vector is defined as

$\boldsymbol{z}_{i}^{\text {nad }}=\sup _{x \in X \text { is Pareto optimal }} f_{i}(x)$ for all $i=1, \ldots, k$

and the ideal objective vector as

$z_{i}^{i d e a l}=\inf _{x \in X} f_{i}(x)$ for all $i=1, \ldots, k$.

This means the components of a Nadir and an ideal objective vector explain upper and lower bounds, respectively, for the values of the objective function of Pareto optimal solutions [39]. In practice, the Nadir objective vector can typically be approximated, as the whole Pareto optimal set is unknown. Besides, a utopian objective vector $z^{\text {utopian }}$ with $\boldsymbol{z}_{i}^{\text {utopian }}=z_{i}^{i d e a l}-\epsilon$ for all $i=1, \ldots, k$,

where $\epsilon>0$ is a small constant, is often defined because of numerical reasons.

\section{The parametric model and design points of the study} As stated before, the present study is conducted to optimize the building shape of a tall rectangular building with horizontal limbs on both sides to reduce wind pressure among the building faces. The detailed specifications of the study building are presented in Table 1 . 
Table 1 Building Specifications

\begin{tabular}{lc}
\hline Parameter & Specifications \\
The rigid Model length scale & $1: 300$ \\
The shape of the building & Rectangular with limbs \\
Length of each limb & $100 \mathrm{~mm}$ \\
Width of each limb & $50 \mathrm{~mm}$ \\
The angle between each limb & $90^{\circ}$ \\
Height of the building & $500 \mathrm{~mm}$ \\
Plan area & $22500 \mathrm{~mm}$ \\
Basic wind speed & $50 \mathrm{~m} / \mathrm{s}$ \\
Velocity scale & $1: 5$ \\
\hline
\end{tabular}

The building model defining building surfaces, dimensions and design variables $X 1, X 2, X 3$ for the optimization study, are shown in Fig. 2. It is worth mentioning that many simplified optimization techniques can achieve the solution to a three-variable optimization problem. However, due to two reasons, the current study uses GA, which is a population-based metaheuristic algorithm. Firstly, the objective functions can adopt complex shapes, needing an evolutionary optimization technique [40] without being stuck in local extreme values. Secondly, the current study needs an optimization technique capable of generating the Pareto-optimal solutions for the multi-objective optimization problem, where the GA is considered appropriate for that application [37].

As shown, $X 1$ and $X 2$ are the distance of the center of the left and right limb, respectively from the center of the rectangular body of the building. The variable $X 3$ is the wind angle of attack (AOA). The unit of $X 1$ and $X 2$ are $\mathrm{mm}$ and $X 3$ is in radian. Concerning the dimensions and configuration of the building, the lower and upper bound of both, $X 1$ and $X 2$ are $0 \mathrm{~mm}$ and $100 \mathrm{~mm}$, respectively, for the optimization study. AOA $(X 3)$ varies from $0^{\circ}$ to $360^{\circ}$, i.e., 0 to 6.28 radian. When both $X 1$ and $X 2$ are 0 , the building becomes '+' plan shaped and when both $X 1$ and $X 2$ are $100 \mathrm{~mm}$, the building becomes $\mathrm{Z}$ plan shaped.

Simple random sampling technique is used to select the design points in the design space. Unlike other forms of design of experiment techniques, simple random sampling is an unbiased approach to gather the responses from a large group. As sample points making up the subset of the larger group are randomly chosen, each point in the population set has an equal probability of being selected. Besides, the random sampling method is much simpler than other methods of sampling. In this study, random sampling is carried out, generating random numbers based on the upper bound and lower bound of the design variables, and 150 design points are selected (Fig. 3). The sample points made through this approach ensured that the entire portion of the design space is epitomized. The values of the objective function are calculated at the design points using RANS k- $\varepsilon$ turbulence model by CFD. These values are used to generate surrogate models of objective functions.

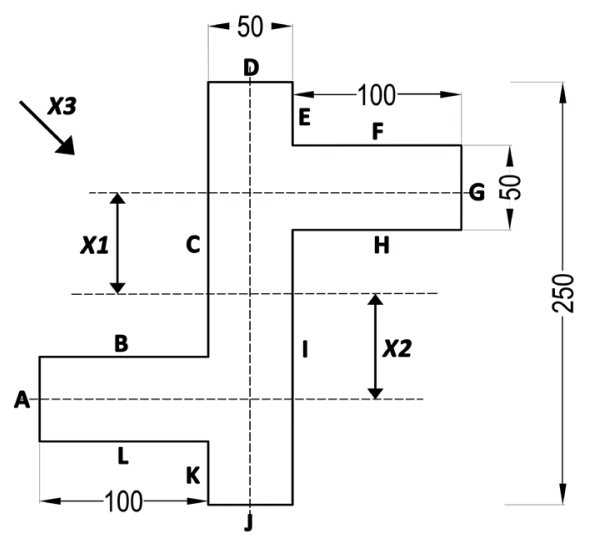

(a)

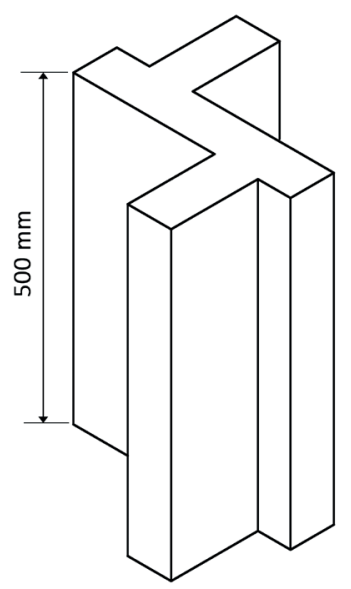

(b)

Fig. 2 Plan and 3-D view of the Parametric model (unit: mm) (a) Plan (b) Isometric View

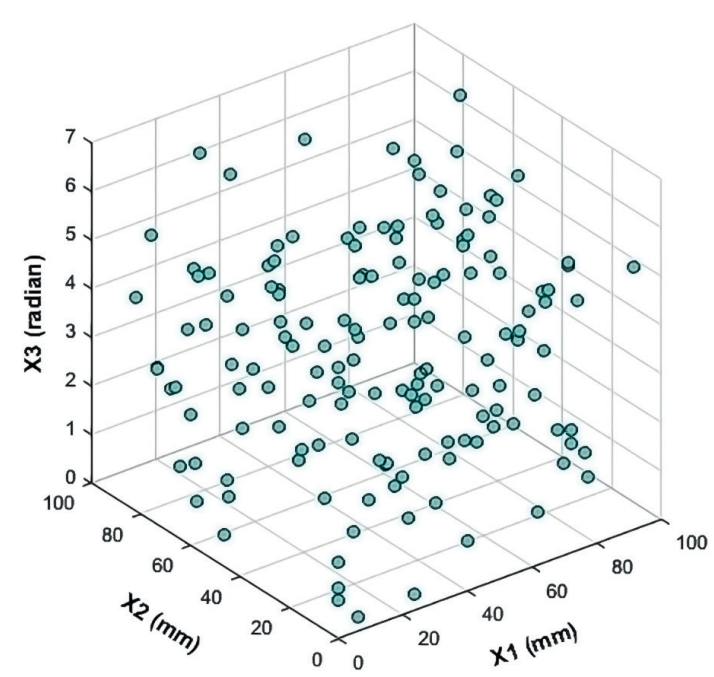

Fig. 3 The design points selected for the study 


\section{Mean wind speed profiles}

Wind velocity is considered to be zero at ground level and continuously increasing from mean wind speed with height. This phenomenon can be expressed by two models, namely logarithmic law as shown in Eq. (1) and power-law, as shown in Eq. (2). Even though there is an effect of earth's frictional resistance on the air movement near the ground surface but at a certain height, the effect is not there. This height varies for different terrain category. The deviation in temperature gives rise of the gradients of pressure which set air in motion.

$\frac{V_{z}}{V^{*}}=\frac{1}{k} \log _{e} \frac{z}{z_{0}}$,

where,

$k=$ Von Karman's constant $=0.40$.

$z=$ height above the ground.

$z_{0}=$ surface roughness parameter.

$V^{*}=$ friction viscosity $=\sqrt{\frac{\tau_{0}}{\rho}}$

$\tau_{0}=$ skin frictional force on wall and $\rho$ is the density of air.

$\frac{V}{V_{0}}=\left(\frac{z}{z_{0}}\right)^{\alpha}$,

where

$V=$ velocity at height $z$ above ground.

$V_{0}=$ wind speed at reference height.

$z_{0}=$ reference height above ground, generally $10 \mathrm{~m}$.

$\alpha=$ exponent power law, varying for different terrain.

Among these two, power-law is more prevalent among researchers, as it is relatively easy to adjust match with mean wind speed profile.

\section{Details of the computational fluid dynamics (CFD)}

Turbulent flow is categorized by muddled deviations of property and a high Reynold's number. The turbulent flow of wind on structures is unbalanced as well as chaotic and kinetic energy is converted to internal energy by viscous shear stress during wind attack. Computational Fluid Dynamics (CFD) is a computer simulation technique in which a 'virtual' wind tunnel is created to envision aerodynamic effects to a specific shape or body. CFD is a convenient and potent methodology that can be adopted to figure out problems connected to complex phenomena of wind-structure interaction when it demands more precise information from the structural safety point of view and occupant comfort criteria. Among many methods in CFD, here ANSYS-CFX is used with $k$ - $\varepsilon$ turbulence modelling keeping sufficient similarity between the model and the prototype. In the turbulence model, $k$ is the kinetic energy of the turbulence defined as the variance of velocity variations and $\varepsilon$ is the dissipated eddies during turbulent flow. Turbulent flows are defined by the very familiar continuity and momentum equations, named after Navier and Stokes, improved to Eq. (3) and Eq. (4) as given below;

$\frac{\partial \rho}{\partial t}+\frac{\partial}{\partial x_{j}}\left(\rho U_{j}\right)=0$

$$
\begin{aligned}
& \frac{\partial \rho U_{i}}{\partial t}+\frac{\partial}{\partial x_{j}}\left(\rho U_{i} U_{j}\right) \\
& \left.=\frac{\partial \dot{P}}{\partial x_{i}}+\frac{\partial}{\partial x_{j}}\left[\mu_{e f f} \frac{\partial U_{i}}{\partial x_{j}}+\frac{\partial U_{j}}{\partial x_{i}}\right)\right]+S_{M},
\end{aligned}
$$

where $S_{M}$ is the sum of the body forces, $\mu_{e f f}$ is the effective viscosity accounting for turbulence, and $p$ is the modified pressure. This $k-\varepsilon$ model is like the zero equation model, based on the eddy viscosity idea. So,

$\mu_{\text {eff }}=\mu+\mu_{t}$,

where $\mu t$ is the turbulence viscosity. The $k-\varepsilon$ model assumes that turbulence viscosity is connected to the turbulence kinetic energy and dissipation by the relation,

$\mu_{t}=C_{\mu} \rho \frac{k^{2}}{\varepsilon}$,

where $C_{\mu}$ is a constant with a value of 0.09 , the values of $k$ and $\varepsilon$ come straight from the differential transport equations for the turbulence kinetic energy and turbulence dissipation rate.

$$
\begin{aligned}
& \frac{\partial(\rho k)}{\partial t}+\frac{\partial}{\partial x_{j}}\left(\rho U_{j} k\right) \\
& =\frac{\partial}{\partial x_{j}}\left[\left(\mu+\frac{\mu_{t}}{\sigma_{k}}\right) \frac{\partial k}{\partial x_{j}}\right]+P_{k}-\rho \varepsilon+P_{k b} \\
& \frac{\partial(\rho \varepsilon)}{\partial t}+\frac{\partial}{\partial x_{j}}\left(\rho U_{j} \varepsilon\right) \\
& =\frac{\partial}{\partial x_{j}}\left[\left(\mu+\frac{\mu_{t}}{\sigma_{\varepsilon}}\right) \frac{\partial \varepsilon}{\partial x_{j}}\right]+\frac{\varepsilon}{k}\left(C_{\varepsilon 1} P_{k}-C_{\varepsilon 3}+C_{\varepsilon 1} P_{\varepsilon b}\right)
\end{aligned}
$$

$P_{k}$ is the turbulence production due to viscous forces, which is modelled by:

$$
P_{k}=\mu_{t}\left(\frac{\partial U_{i}}{\partial x_{j}}+\frac{\partial U_{j}}{\partial x_{i}}\right) \frac{\partial U_{i}}{\partial x_{j}}-\frac{2}{3} \frac{\partial U_{k}}{\partial x_{k}}\left(3 \mu_{t} \frac{\partial U_{k}}{\partial x_{k}}+\rho k\right)
$$


$C_{\varepsilon 1}$ and $C_{\varepsilon 2}$ are also $k-\varepsilon$ turbulence model constants in ANSYS CFX with values of 1.44 and 1.92, respectively. $\sigma_{k}$ is the turbulence model constant having a value of 1.0, and $\varepsilon_{k}$ is also a turbulence model constant with a value of $1.30 . \rho$ is the density of air considered as $1.224 \mathrm{~kg} / \mathrm{m}^{3}$. The turbulence viscosity is denoted with $\mu_{t}$. The buildings are taken as bluff body and streamlines near the building is studied. Turbulence intensity is taken as $1 \%$. Wind velocity at the inlet is considered as $10 \mathrm{~m} / \mathrm{s}$ considering $1: 5$ velocity scale.

\subsection{Domain used for the CFD study}

A reasonably substantial computational domain invariably leads to a large cell count after meshing the entire domain with many of the cells in the grid being used up in regions far from the building surfaces or wake region. Hence the domain size for CFD, especially for a tall building shall be chosen rationally so that the analysis time does not increase needlessly. Revuz et al. [41] prescribed the suitable domain size for tall buildings considering the effects of varying the domain size around a tall building. They took into account the generation of vortices and fluctuations in velocity in the region of disturbed flow downstream of the building caused by the wind flow are derived with sufficient accuracy. They recommended the domain size having an inlet, top and two side clearance of $15 \mathrm{H}$ and outlet clearance of $5 \mathrm{H}$ from the building edges, where $H$ is the building height. The domain used for the study is shown in Fig. 4(a) and Fig. 4(b).

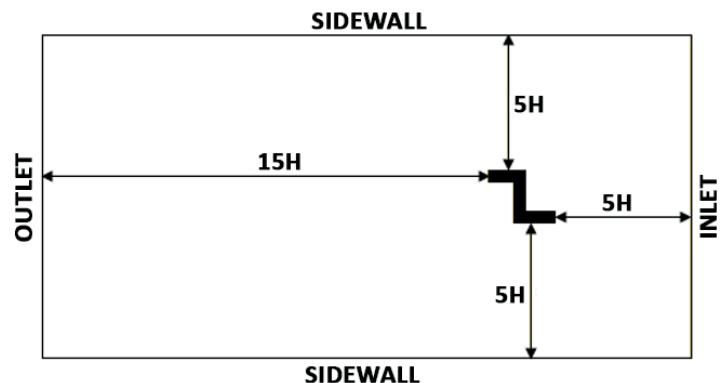

(a)

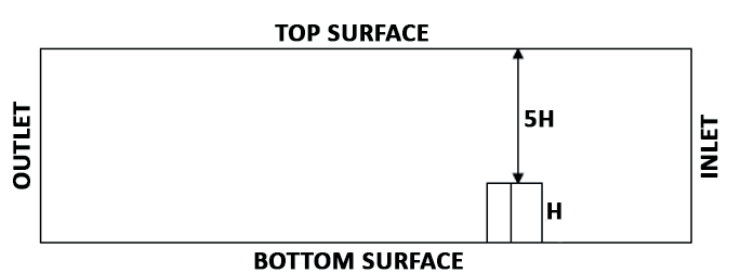

(b)

Fig. 4 (a) Plan of the domain used for the study, (b) Elevation of the domain used for the study

\subsection{Grid independence test and meshing for CFD}

Grid independence is an essential criterion in any CFD method to derive the conclusion that further reduction in grid size does not lead to any more precision in the results. The grid independence test is carried out by trial and error method decreasing the grid size in each trial resulting subsequent increase in the number of elements in the domain. An amalgamation of tetrahedral meshing and hexahedral meshing is used to mesh the entire domain as well as the building walls. Very fine hexahedral meshes are generated close to the building surfaces to help in simulating even flow. Uniform coarser tetrahedral meshing in rest of the domain is taken up to lessen the time of analysis. The first grid points adjoining the wall are located at $y^{+}>30$ to implement empirical wall functions. Initially, a $Z$ shaped building model is designed in the pre-processing software ANSYS CFX - CFD. Three different mesh patterns, namely coarse grid, medium grid and fine grid, are generated. The grid patters with an enlarged view of a corner are shown in Figs. 5(a)-(c). The number of elements in the coarse, medium and fine grids are $4.96 \times 10^{6}, 8.13 \times 10^{6}$ and $1.18 \times 10^{7}$, respectively.

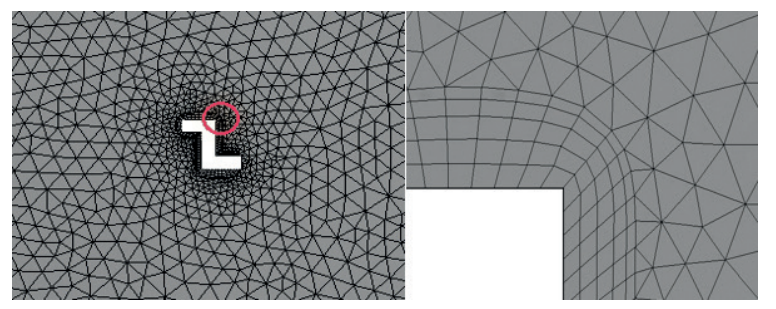

(a)

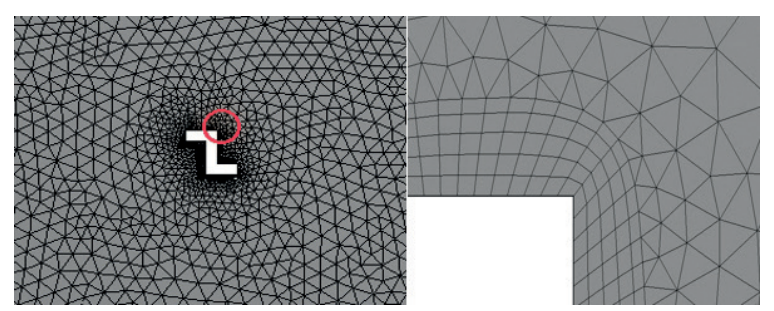

(b)

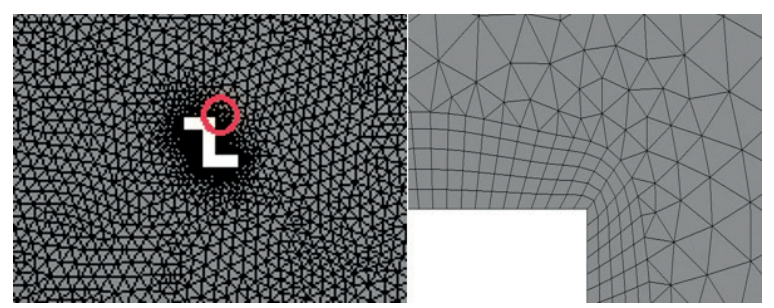

(c)

Fig. 5 Different mesh patterns used for the grid independence test; a) Coarse grid, b) Medium grid, c) Fine grid 


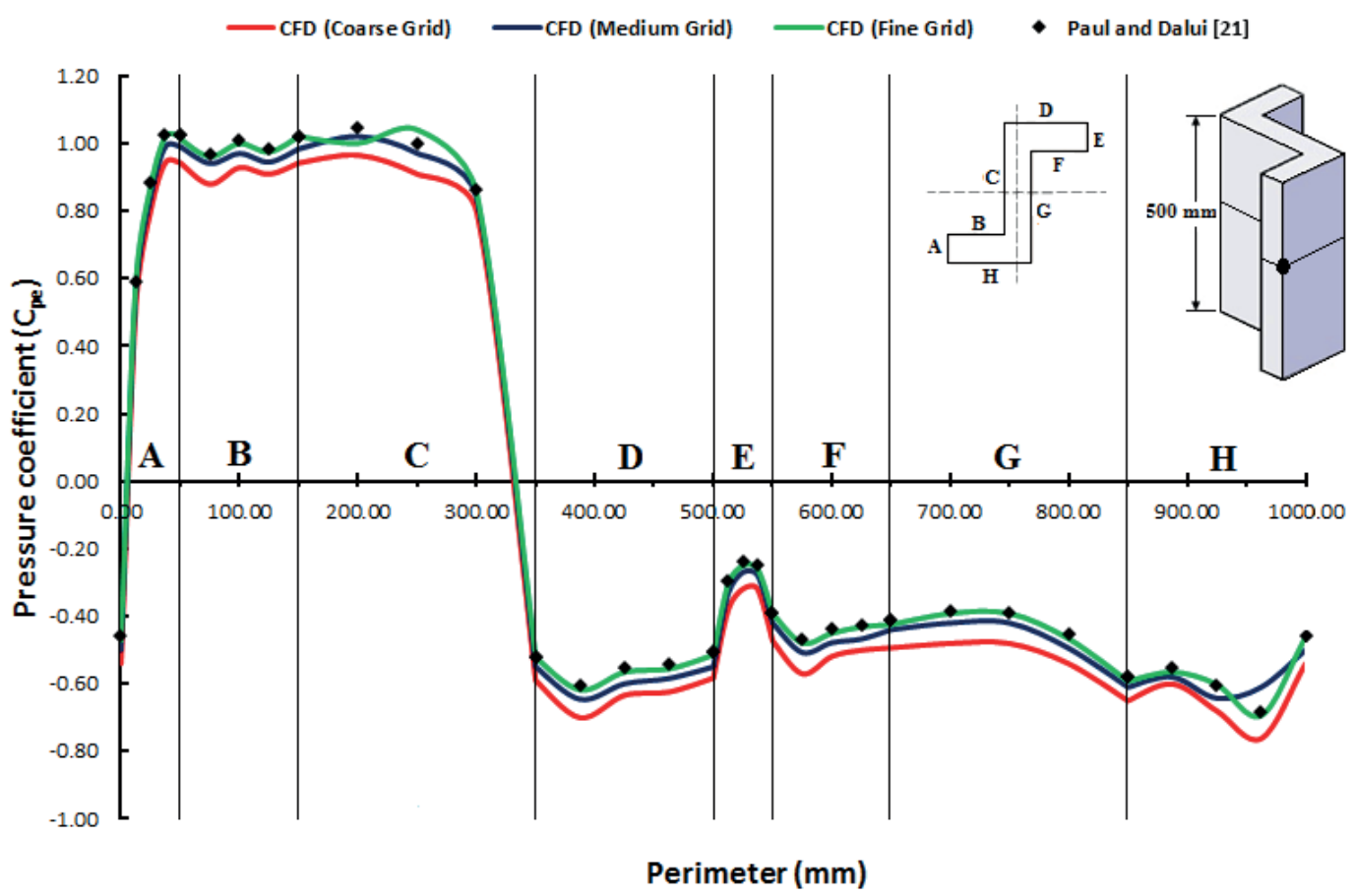

Fig. 6 Variation of pressure coefficients through the perimeter for different mesh patterns for $0^{\circ}$ wind angle

The pressure coefficients through the perimeter of all the faces at the height of $270 \mathrm{~mm}$ corresponding to $0^{\circ}$ wind incidence angle are computed for all mesh patterns. The results are compared with the results of Paul and Dalui [21]. The pressure variation in each case is shown in Fig. 6. As expected, most accurate results with minimal percentages of error are obtained for fine mesh, but in the case of medium meshing, the results are also good. Medium meshing is considered for any simulation in the rest of the study to speed up the analysis without significant loss of accuracy in the results.

\subsection{Boundary conditions}

A high degree of similitude between the boundary conditions of both the numerical and the experimental methods should be achieved mainly for inlet or inflow boundary. The boundary layer flow is generated using power-law with $\alpha=0.133$ to attain the desired terrain category as per IS 875-3 (Part 3) [42]. The velocity profile in the vicinity of the windward side as obtained from the numerical method and wind tunnel measurement are nearly alike as observed from Fig. 7 [43]. The turbulence intensity along the building height is also compared for numerical method and wind tunnel measurement and is presented in Fig. 8 [43]. The turbulence intensity is also matching with good agreement for both methods.

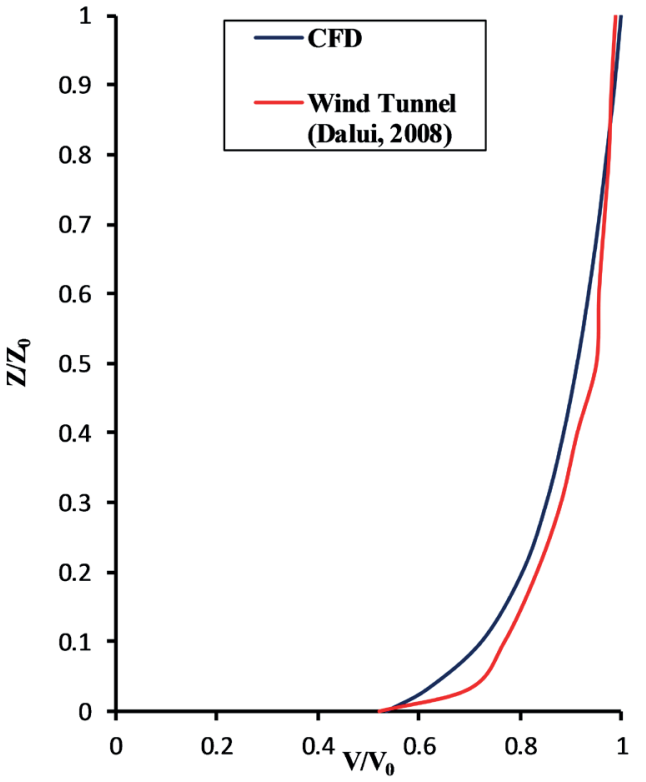

Fig. 7 The velocity profile

\section{Calibration of CFD}

Calibration of the CFD package has been done by carrying out a numerical study of a RANS $k-\varepsilon$ turbulence model of a square building. For a square building of particular aspect ratio $(h / w=5)$, pressure coefficients are given in IS 875-3 (Part 3) [42]. Numerical analysis has been conducted in ANSYS CFX software for similar building model under comparable wind environment to obtain the external 


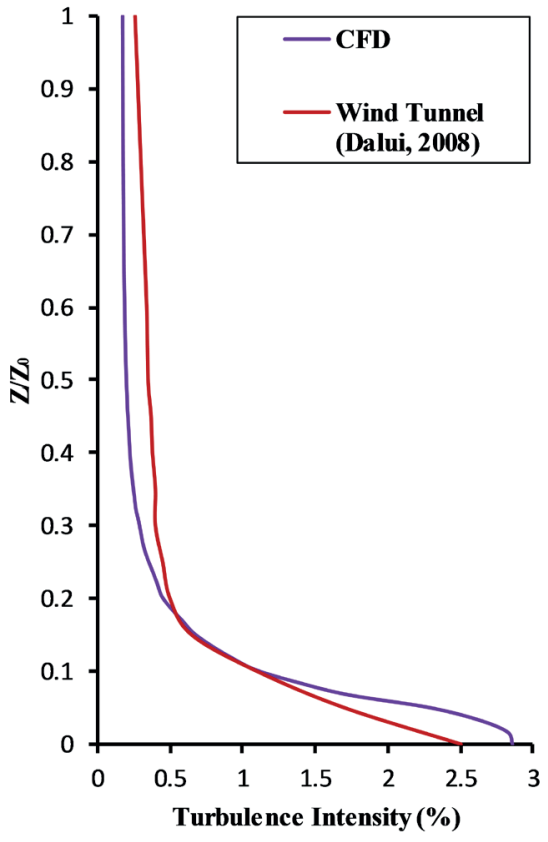

Fig. 8 Turbulence intensity

pressure coefficients on different faces of the building. The results are compared with some other international standards of wind load evaluation too.

Table 2 shows the comparison of the external pressure coefficient $C_{p e}$ between different international standards of wind load and $C_{p e}$ calculated by ANSYS CFX for a square building. The results of numerical analysis and the provisions of the code ASCE 7-10 [44] and AS-NZS 11702:2002 [45] are closely matched. For the windward face (Face A), there is $0 \%$ deviation in the result. Again for the sidewalls, the variation is $7.7 \%$ and $14.3 \%$ concerning AS-NZS 1170-2:2002 and ASCE 7-10 respectively. But for leeward face, the result from ANSYS is deviating $20 \%$ concerning both the codes. This deviation in result possibly due to the generation of unstable vortices in the wake region near the leeward face.

\section{Results and discussions}

As discussed earlier, the mean pressure coefficients, $C_{p e}$ on building surfaces are obtained from the numerical simulation at the design points. RSA models of the objective functions are constructed using the function values generated from CFD. For the construction of RSA models, Eq. (3) given in Section 2.1 is used. The RSA models of $C_{p e}$ for different faces of the building with the corresponding $R^{2}$ values are presented in Table 3. All $R^{2}$ values are more than 0.90 , which is acceptable with good agreement to construct an analytical model.

\subsection{Validation of the RSA models}

The surrogate models as obtained for different faces of the building are validated for the ' + ' shaped tall building. Chakraborty et al. [18, 19] presented the external pressure coefficients $\left(C_{p e}\right)$ on different faces of a 't' shaped tall building obtained from Wind Tunnel and k- $\varepsilon$ Numerical Simulation. The height-ratio and the plan-ratio of the building are similar to the parametric models adopted for the present study. The ' + ' shaped model defining building surfaces, dimensions and wind incidence angles are shown in Fig. 9 (The wind angles and the building surfaces are designated comparing the present study). The experiment was carried out in the boundary layer wind tunnel (BLWT) at Wind Engineering Centre, Department of Civil Engineering, Indian Institute of Technology Roorkee, India $[18,19]$. The BLWT was an open circuit suction type tunnel in which the suction flow was generated with a blower fan of 125 HP capacity $[18,19]$. The test section was $2 \mathrm{~m}$ (height) $\times 2 \mathrm{~m}$ (width) $\times 38 \mathrm{~m}$ (length) $[18,19]$. An elliptical effuse profile having a contraction ratio of 9.5:1 along with a $6 \mathrm{~m} \times 6 \mathrm{~m}$ squared-holed Honeycomb was located at the entrance of the tunnel $[18,19]$.

Table 2 Surface pressure coefficients for a square building

\begin{tabular}{|c|c|c|c|c|c|c|c|}
\hline \multirow{2}{*}{ Plan of the Building } & \multirow{2}{*}{ As Per } & \multirow{2}{*}{$h_{/ w}$} & \multirow{2}{*}{$\begin{array}{c}\text { Wind Angle } \\
\qquad(\theta)\end{array}$} & \multicolumn{4}{|c|}{ Cpe for surfaces } \\
\hline & & & & A & B & $\mathrm{C}$ & D \\
\hline \multirow{4}{*}{$\mathrm{C}$} & \multirow{2}{*}{ ANSYS CFX } & \multirow{2}{*}{$h_{w}=5$} & $0^{\circ}$ & +0.80 & -0.40 & -0.60 & -0.60 \\
\hline & & & $90^{\circ}$ & -0.60 & -0.60 & +0.80 & -0.40 \\
\hline & \multirow{2}{*}{$\begin{array}{c}\text { AS-NZS } \\
1170-2: 2002\end{array}$} & \multirow{2}{*}{$\begin{array}{l}\text { Any } \\
h / w\end{array}$} & $0^{\circ}$ & +0.80 & -0.50 & -0.65 & -0.65 \\
\hline & & & $90^{\circ}$ & -0.65 & -0.65 & +0.80 & -0.50 \\
\hline \multirow[t]{4}{*}{$\mathrm{A}$} & \multirow{2}{*}{ ASCE 7-10 } & \multirow{2}{*}{$\begin{array}{l}\text { Any } \\
h / w\end{array}$} & $0^{\circ}$ & +0.80 & -0.50 & -0.70 & -0.70 \\
\hline & & & $90^{\circ}$ & -0.70 & -0.70 & +0.80 & -0.50 \\
\hline & \multirow{2}{*}{$\begin{array}{c}\text { IS: } 875 \text { (Part } \\
\text { 3) - } 2015\end{array}$} & \multirow{2}{*}{$3 / 2<h / w=6$} & $0^{\circ}$ & +0.80 & -0.25 & -0.80 & -0.80 \\
\hline & & & $90^{\circ}$ & -0.80 & -0.80 & +0.80 & -0.25 \\
\hline
\end{tabular}


Table 3 RSA Models of Cpe for different faces of the building

\begin{tabular}{|c|c|c|}
\hline Objective function $C_{p e}$ for & RSA model & $R^{2}$ \\
\hline Face A & $\begin{array}{l}0.4705+0.00027 X 1+0.01498 X 2-0.82201 X 3+0.00005 X 1^{2}-0.00011 X 2^{2}+0.14277 X 3^{2} \\
-0.00002 X 1 X 2-0.00225 X 1 X 3-0.00068 X 2 X 3\end{array}$ & 0.9481 \\
\hline Face B & $\begin{array}{l}-0.3461-0.01457 X 1+0.00072 X 2-0.179 X 3+0.00015 X 1^{2}+0.00021 X 2^{2}+0.09047 X 3^{2} \\
-0.00014 X 1 X 2+0.00284 X 1 X 3-0.00536 X 2 X 3\end{array}$ & 0.9960 \\
\hline Face $\mathrm{C}$ & $\begin{array}{l}-0.24581-0.01341 X 1+0.00349 X 2-0.27421 X 3+0.00016 X 1^{2}+0.00016 X 2^{2}+0.09612 X 3^{2} \\
-0.00014 X 1 X 2+0.00123 X 1 X 3-0.0035 X 2 X 3\end{array}$ & 0.9977 \\
\hline Face D & $\begin{array}{l}-0.30202-0.0187 X 1-0.01802 X 2-0.03886 X 3+0.00021 X 1^{2}+0.00022 X 2^{2}-0.00116 X 3^{2} \\
-0.00009 X 1 X 2+0.00083 X 1 X 3+0.00299 X 2 X 3\end{array}$ & 0.9959 \\
\hline Face E & $\begin{array}{l}-0.0755-0.03272 X 1-0.02573 X 2-0.22093 X 3+0.00036 X 1^{2}+0.00041 X 2^{2}+0.03373 X 3^{2} \\
-0.0002 X 1 X 2+0.00289 X 1 X 3+0.0011 X 2 X 3\end{array}$ & 0.9983 \\
\hline Face F & $\begin{array}{l}0.19502-0.01763 X 1-0.0158 X 2-0.04477 X 3+0.00012 X 1^{2}+0.0002 X 2^{2}-0.00443 X 3^{2} \\
-0.00003 X 1 X 2+0.00297 X 1 X 3+0.00073 X 2 X 3\end{array}$ & 0.9757 \\
\hline Face G & $\begin{array}{l}-0.32672-0.02056 X 1+0.00969 X 2-0.01908 X 3+0.00008 X 1^{2}-0.00006 X 2^{2}-0.01606 X 3^{2} \\
+0.00004 X 1 X 2+0.00568 X 1 X 3+0.00151 X 2 X 3\end{array}$ & 0.9139 \\
\hline Face $\mathrm{H}$ & $\begin{array}{l}-1.57938+0.00475 X 1+0.00949 X 2+1.60478 X 3-0.00012 X 1^{2}-0.00002 X 2^{2}-0.22898 X 3^{2} \\
+0.00004 X 1 X 2+0.00286 X 1 X 3-0.00641 X 2 X 3\end{array}$ & 0.9903 \\
\hline Face I & $\begin{array}{l}-1.69497+0.00353 X 1+0.0248 X 2+1.669 X 3-0.00033 X 1^{2}+-0.00027 X 2^{2}-0.23795 X 3^{2} \\
+0.00039 X 1 X 2+0.00362 X 1 X 3-0.00819 X 2 X 3\end{array}$ & 0.9073 \\
\hline Face $\mathrm{J}$ & $\begin{array}{l}-0.49914+0.01879 X 1-0.07951 X 2+0.8401 X 3-0.00019 X 1^{2}+0.00074 X 2^{2}-0.0614 X 3^{2} \\
+0.0001 X 1 X 2+0.00209 X 1 X 3-0.00797 X 2 X 3\end{array}$ & 0.9882 \\
\hline Face K & $\begin{array}{l}0.98314+0.00253 X 1-0.03056 X 2-0.41111 X 3-0.00001 X 1^{2}+0.0001 X 2^{2}+0.03895 X 3^{2} \\
+0.00014 X 1 X 2-0.00175 X 1 X 3+0.00214 X 2 X 3\end{array}$ & 0.9623 \\
\hline Face L & $\begin{array}{l}0.92371+0.00617 X 1-0.02748 X 2-0.332 X 3-0.00005 X 1^{2}+0.00006 X 2^{2}+0.01799 X 3^{2} \\
+0.00011 X 1 X 2-0.00189 X 1 X 3+0.0034 X 2 X 3\end{array}$ & 0.9369 \\
\hline
\end{tabular}

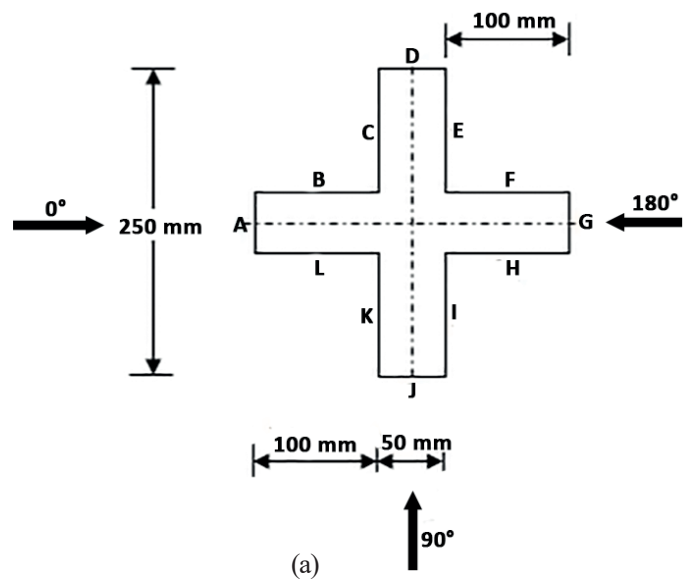

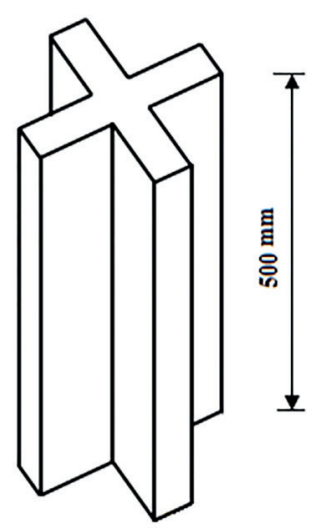

(b)

Fig. 9 Plan and Isometric view of the '+' shaped building model, (a) Plan, (b) Isometric view

RSA models are compared for wind incidence angle $45^{\circ}, 60^{\circ}$ and $90^{\circ}$ and are presented in Table 4 . For $45^{\circ}$ wind incidence angle, the discrepancy in the result is on the higher side for Face J. For all other faces, the results obtained are having a good agreement with experimental results. Again for $60^{\circ}$ wind incidence, some deviations in results are observed for Face A and Face I of the building. While for the other faces, good results are achieved. As the surrogate models are constructed by the approximation method, some results had some percentage of discrepancy compared with the actual data. At $90^{\circ}$ wind angle of occurrence, the values of the pressure coefficients obtained from surrogate models for all the faces are reasonably good as compared with the wind tunnel data.

\subsection{Surface plots of objective functions}

Fig. 10(a)-(1) shows the surface plots of external pressure coefficient for Face A to Face L respectively, corresponding to the range of upper and lower bound of the design variables $X 1$ and $X 2$ at $0^{\circ}$ wind incidence angle. Similarly, response surfaces corresponding to any wind occurrence angle can be achieved from the proposed RSA models. 
Table 4 Comparison of the values of the objective functions $C_{p e}$ for ' + ' $(X 1=0$ and $X 2=0)$ shaped tall building for various wind angle of attack

\begin{tabular}{|c|c|c|c|c|c|c|}
\hline \multirow{2}{*}{ Location } & \multicolumn{2}{|c|}{ Wind angle $45^{\circ}$} & \multicolumn{2}{|c|}{$\begin{array}{c}C_{p e} \\
\text { Wind angle } 60^{\circ}\end{array}$} & \multicolumn{2}{|c|}{ Wind angle $90^{\circ}$} \\
\hline & $\begin{array}{c}\text { Wind Tunnel } \\
{[18,19]}\end{array}$ & $\begin{array}{l}\text { Surrogate Model } \\
\text { (Present study) }\end{array}$ & $\begin{array}{c}\text { Wind Tunnel } \\
{[18,19]}\end{array}$ & $\begin{array}{l}\text { Surrogate Model } \\
\text { (Present study) }\end{array}$ & $\begin{array}{c}\text { Wind Tunnel } \\
{[18,19]}\end{array}$ & $\begin{array}{l}\text { Surrogate Model } \\
\text { (Present study) }\end{array}$ \\
\hline Face A & -0.10 & -0.09 & -0.27 & -0.23 & -0.41 & -0.47 \\
\hline Face B & -0.46 & -0.43 & -0.42 & -0.43 & -0.35 & -0.40 \\
\hline Face $\mathrm{C}$ & -0.41 & -0.40 & -0.44 & -0.43 & -0.38 & -0.44 \\
\hline Face D & -0.33 & -0.33 & -0.33 & -0.34 & -0.34 & -0.37 \\
\hline Face E & -0.25 & -0.23 & -0.26 & -0.27 & -0.38 & -0.34 \\
\hline Face F & -0.25 & -0.23 & -0.24 & -0.25 & -0.35 & -0.28 \\
\hline Face G & -0.33 & -0.35 & -0.35 & -0.36 & -0.41 & -0.40 \\
\hline Face H & -0.41 & -0.46 & -0.19 & -0.15 & 0.43 & 0.38 \\
\hline Face I & -0.46 & -0.53 & -0.38 & -0.21 & 0.38 & 0.34 \\
\hline Face J & -0.10 & 0.12 & 0.38 & 0.31 & 0.65 & 0.67 \\
\hline Face K & 0.66 & 0.68 & 0.64 & 0.60 & 0.38 & 0.43 \\
\hline Face L & 0.66 & 0.67 & 0.66 & 0.60 & 0.43 & 0.46 \\
\hline
\end{tabular}

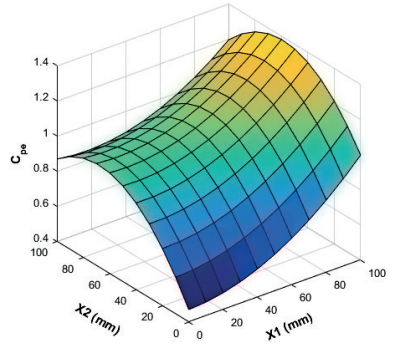

(a) Face $\mathrm{A}$

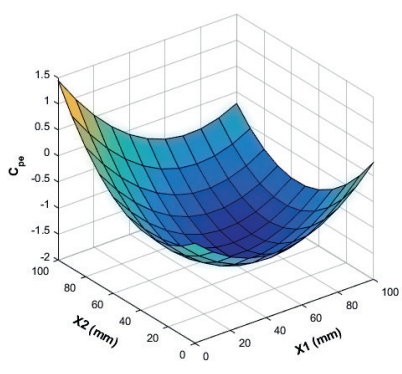

(e) Face $\mathrm{E}$

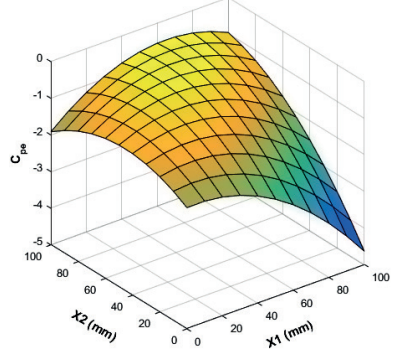

(i) Face I

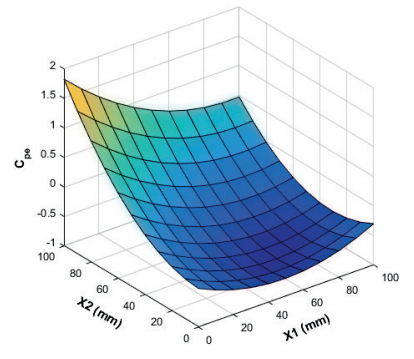

(b) Face B

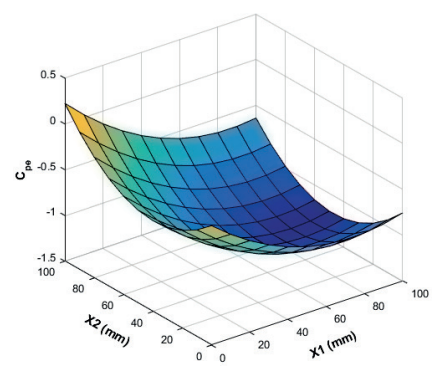

(f)Face $\mathrm{F}$

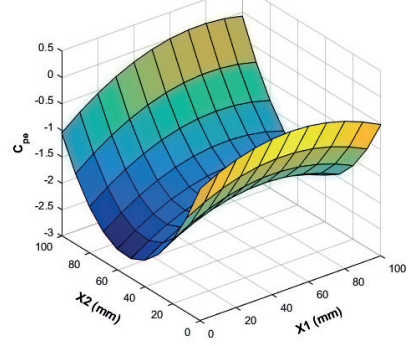

(j) Face J

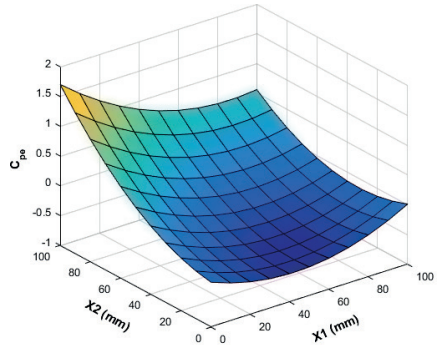

(c) Face C

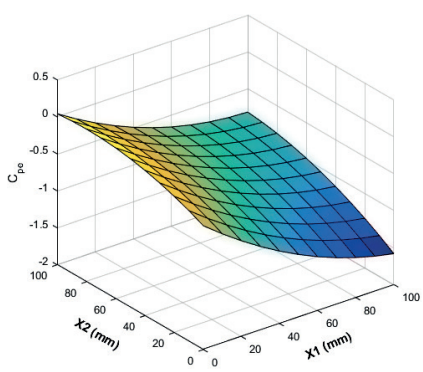

(g) Face G

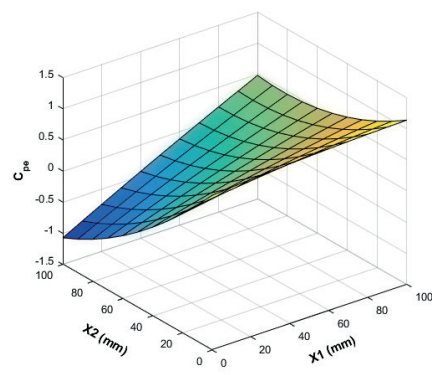

(j) Face $\mathrm{K}$

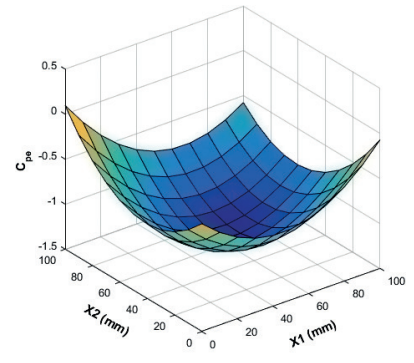

(d) Face D

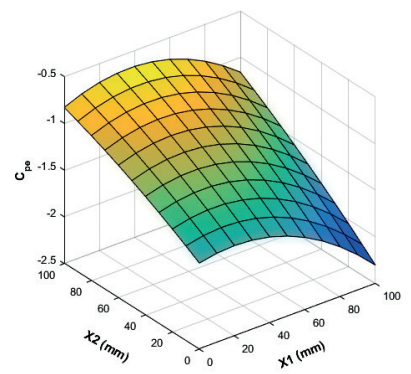

(h) Face $\mathrm{H}$

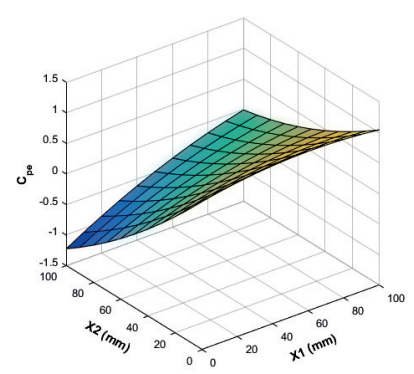

(j) Face L

Fig. 10 Response Surface of $C_{p e}$ for different faces for $0^{\circ}$ wind angle of attack 


\subsection{Results of optimization}

A multi-objective optimization study is carried out based on the surrogate models to optimize the mean pressure coefficients $C_{p e}$ of all the building facetstogether. As discussed, for multi-objective optimization problems, one objective cannot be improved without sacrificing others and hence the concept of Pareto optimal design solutions is used. The optimization commences with the formation of an initial population comprising of 200 different combinations of the design variables. The RSA models are used as the surrogates of the multi-objective Genetic Algorithm (MOGA). The maximum number of generations is limited to 1200 . The details of the MOGA setup are given in Table 5. The global Pareto-optimal solutions with design results are obtained using MOGA and presented in Figs. 11(a)-(j). The Pareto solutions composed of
10 candidates are optimal in the sense that other solutions in the design space are not superior to them. Depending on the architectural requirement, one of the proposed optimal shapes may be chosen to decrease the cost-benefit ratio of the project.

Table 5 Details of the MOGA setup

\begin{tabular}{lc}
\hline Parameter & Specification \\
\hline population size & 200 \\
number of generations & 1200 \\
Number of objectives in the fitness function & 12 \\
Number of variables in the fitness function & 3 \\
Lower Bound & {$[0,0,0]$} \\
Upper Bound & {$[100,100,6.28]$} \\
cross-over rate & 0.8 \\
Mutation function & Constraint dependent \\
\hline
\end{tabular}

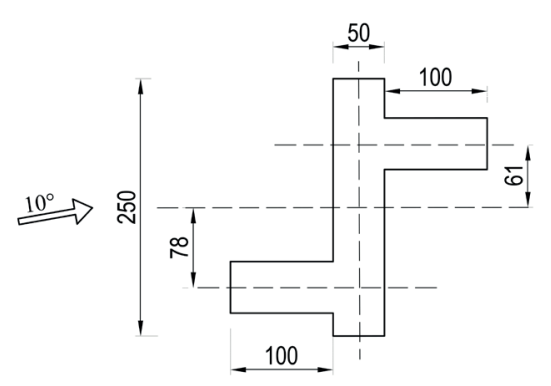

(a) Pareto-optimal solution-1

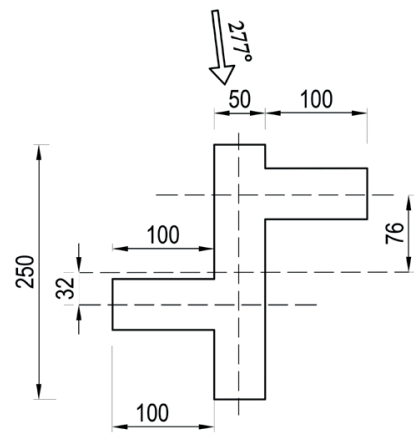

(d) Pareto-optimal solution-4

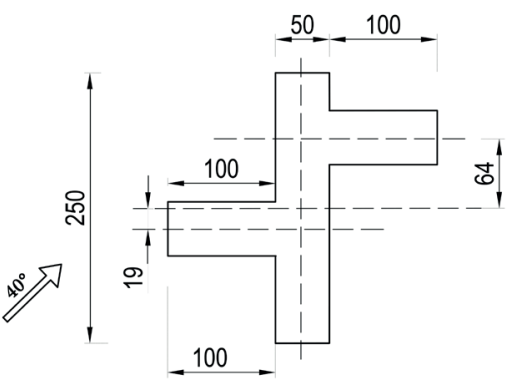

(b) Pareto-optimal solution-2

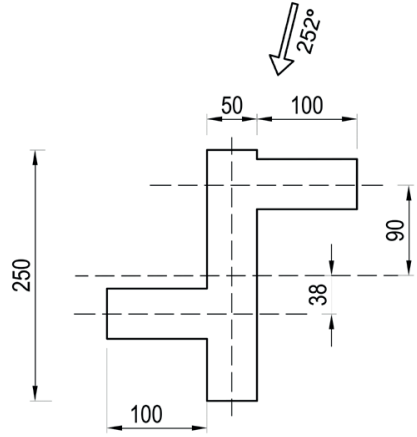

(c) Pareto-optimal solution-3

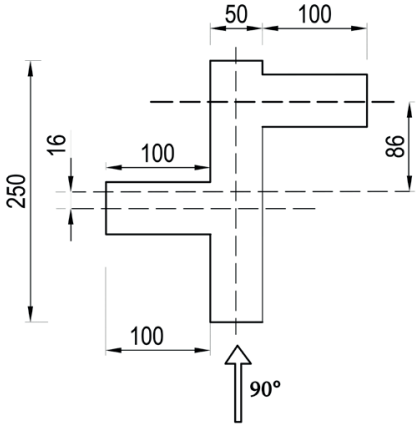

(e) Pareto-optimal solution-5

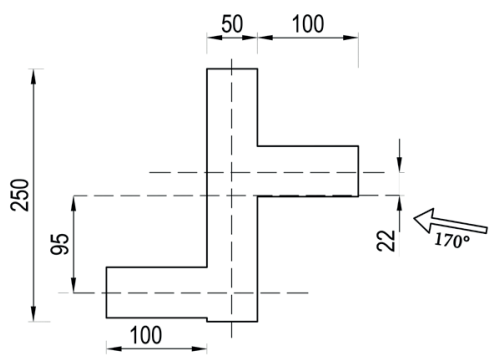

(f) Pareto-optimal solution-6

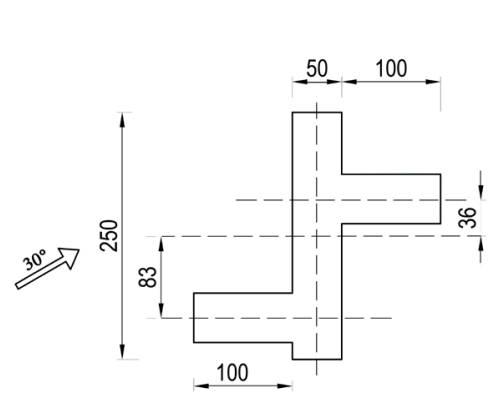

(g) Pareto-optimal solution-7

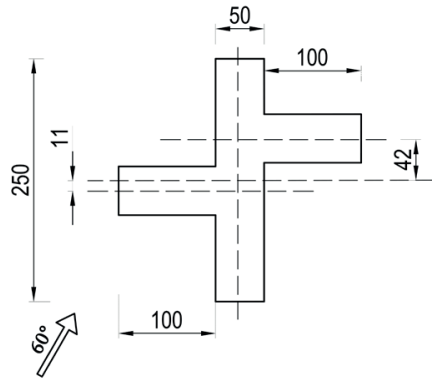

(h) Pareto-optimal solution-8

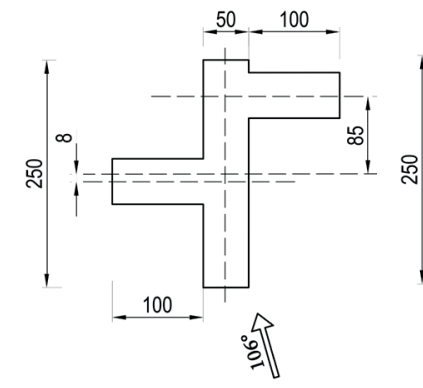

(i) Pareto-optimal solution-9

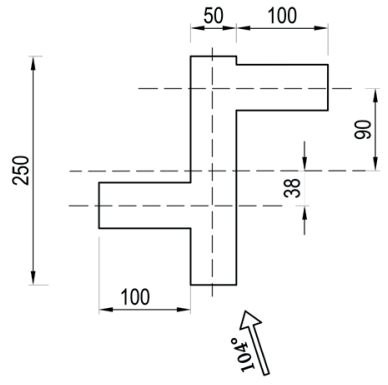

(j) Pareto-optimal solution-10

Fig. 11 Pareto-optimal solutions of the study depicting decision variables (unit: $\mathrm{mm}$ ) 
Further validation is essential to adjudge the accuracy of the optimization study. The function values, as obtained from the MOGA optimization study at the decision variable, are verified by carrying out a CFD study. A numerical study is performed using RANS $k-\varepsilon$ turbulence model for the proposed Pareto-optimal shapes of the building. Mean pressure coefficient $\left(C_{p e}\right)$ on the different building facets of the models are determined. The results of CFD are compared with the results of MOGA for the defined building surfaces and presented in Fig. 12(a) to Eq. (1). It is observed that the function values achieved from the MOGA study and the results of the numerical study are nearly overlying each other, ensuring a satisfactory level of precision of the optimization study.

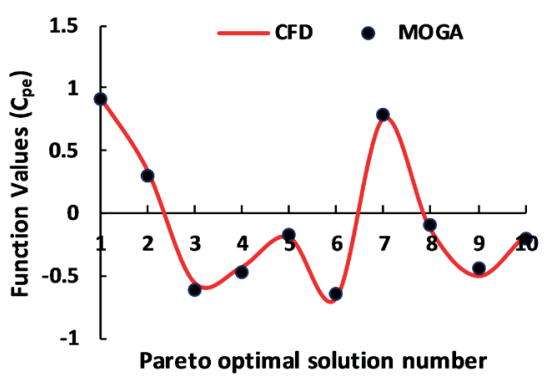

(a) Face $\mathrm{A}$

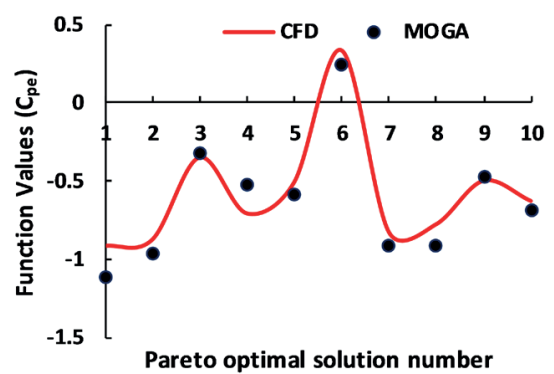

(a) Face D

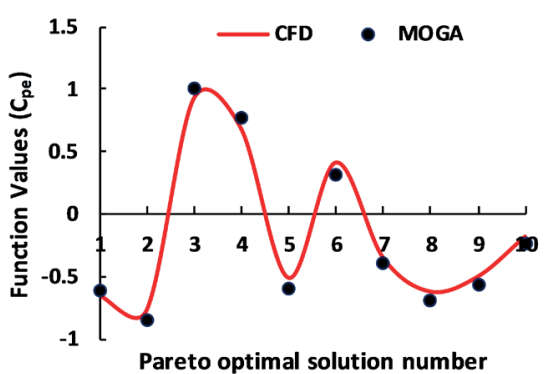

(a) Face $\mathrm{G}$

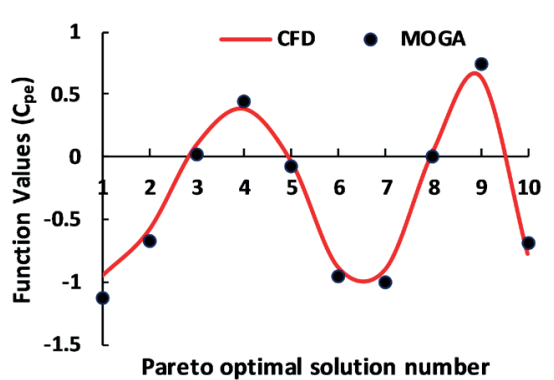

(a) Face J

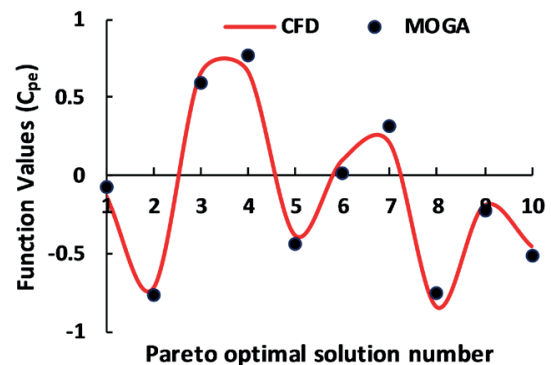

(a) Face B

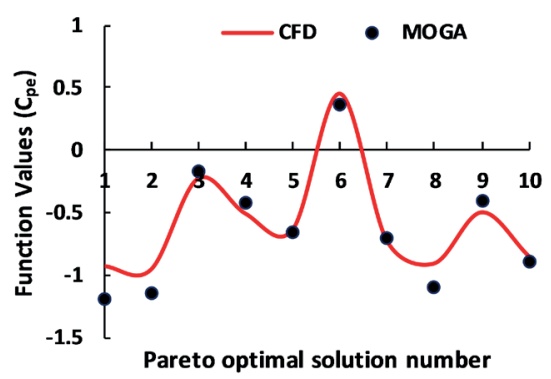

(a) Face $\mathrm{E}$

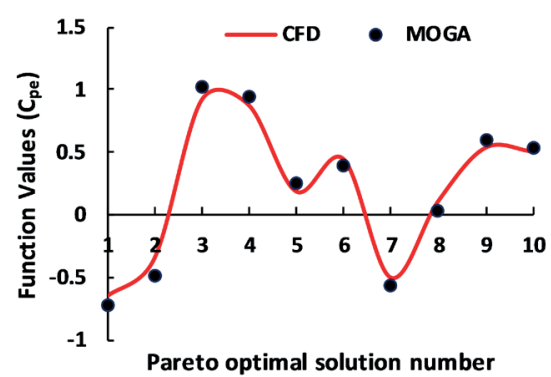

(a) Face $\mathrm{H}$

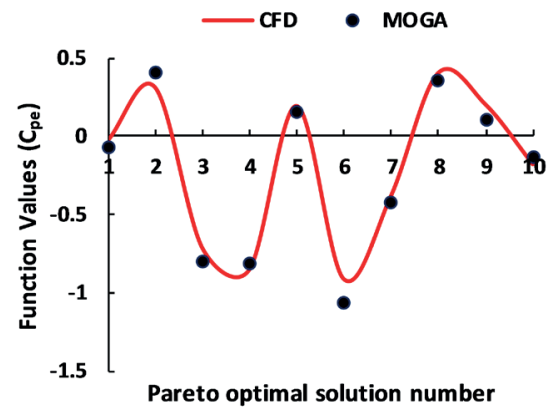

(a) Face $\mathrm{K}$

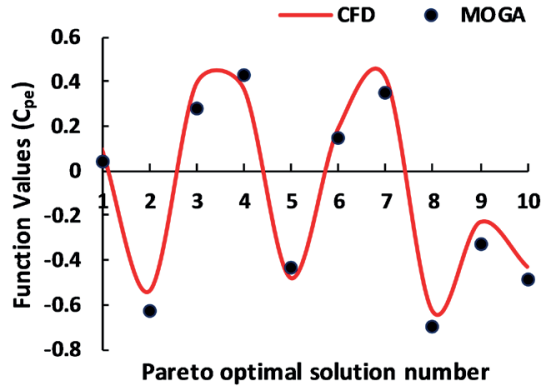

(a) Face C

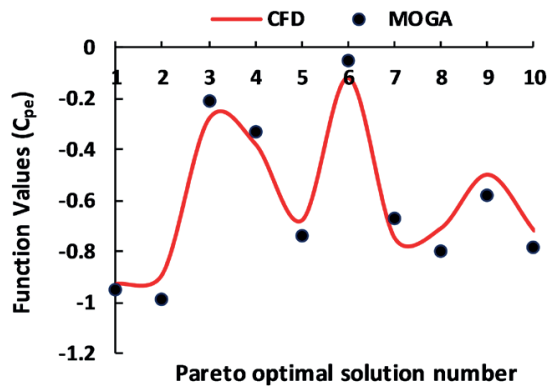

(a) Face $\mathrm{F}$

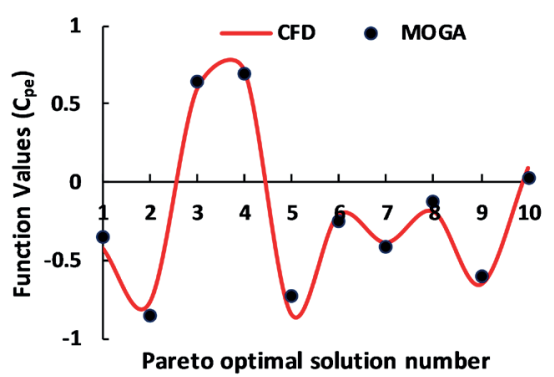

(a) Face I

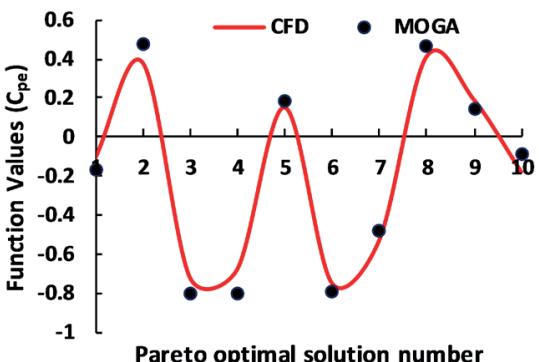

(a) Face L

Fig. 12 The comparison of pressure coefficients obtained using the MOGA and CFD methods 


\section{Conclusions}

In this article, shape optimization under wind excitation is carried out for a rectangular plan shaped building with horizontal limbs on both sides for minimization of external pressure on different surfaces of the building together. The novelty of the study lies in the selection of the building shape. This particular shape is critical due to its increasing popularity among commercial buildings. Multi-objective optimization is performed using surrogate modelling and a MOGA algorithm with 3D unsteady CFD analysis. RANS $k-\varepsilon$ turbulence models are considered for CFD, and the RSA method is used to construct the surrogate models of the pressure coefficients. The results of RSA models are compared with the wind tunnel results of a ' + ' shaped building, and there is almost no or insignificant discrepancy found in the results obtained. For an unusual plan shaped tall buildings, international standards recommend either experimental or numerical model analysis. The experimental method of carrying out the wind pres-

\section{References}

[1] Murakami, S. (ed.) "Computational Wind Engineering I, Proceedings of the 1st International Symposium on Computational Wind Engineering (CWE 92)", Elsevier Science, Amsterdam, The Netherlands, 1993.

https://doi.org/10.1016/C2009-0-10273-8

[2] Meroney, R., Bienkiewicz, B. (eds.) "CWE-96: Computational Wind Engineering II, Proceedings of the 2nd International Symposium on Computational Wind Engineering (CWE 96)", Elsevier Science, Amsterdam, The Netherlands, 1997.

[3] Kareem, A. "The effect of Aerodynamic interference on the dynamic response of prismatic structures", Journal of Wind Engineering and Industrial Aerodynamics, 25(3), pp. 365-372, 1987. https://doi.org/10.1016/0167-6105(87)90028-6

[4] Liang, S., Li, Q. S., Lui, S., Zhang, L., Gu, M. "Torsional dynamic wind loads on rectangular tall buildings", Engineering Structures, 26(1), pp. 129-137, 2004.

https://doi.org/10.1016/j.engstruct.2003.09.004

[5] Lin, N., Letchford, C., Tamura, Y., Liang, B., Nakamura, O. "Characteristics of wind forces acting on tall buildings", Journal of Wind Engineering and Industrial Aerodynamics, 93(3), pp. 217-242, 2004. https://doi.org/10.1016/j.jweia.2004.12.001

[6] Gomes, M. G., Rodrigues, A. M., Mendes, P. "Experimental and numerical study of wind pressures on irregular-plan shapes", Journal of Wind Engineering and Industrial Aerodynamics, 93(10), pp. 741756,2005

https://doi.org/10.1016/j.jweia.2005.08.008

[7] Lam, K. M., Zhao, J. G. "Interference effects of wind loads on a row of tall buildings", In: The Fourth International Symposium on Computational Wind Engineering (CWE2006), Yokohama, Japan, 2006, pp. 817-820. sure coefficients of a tall building is the wind tunnel test which is expensive, cumbersome and time-consuming. Nowadays numerical simulation method creating a virtual wind tunnel has become popular, which consumes lesser time compared to wind tunnel method. Even for numerical simulation also, a significant amount of cost and time is needed. The RSA models of external pressure coefficients $\left(C_{p e}\right)$ provided in this study may readily be used for the design of structural elements of rectangular plan shaped buildings with horizontal limbs.

This particular study involving CFD, RSA and GA, making optimization of the aerodynamic shape can be beneficial in the actual design against wind load. The Pareto-optimal design results are presented in this article with function values and decision variables. The function values are verified by introducing a separate CFD study. Hence, a designer can select one of the Pareto-optimal designs based on their architectural preference.

[8] Irwin, P. A. "Bluff body aerodynamics in wind engineering", Journal of Wind Engineering and Industrial Aerodynamics, 96(6-7), pp. 701-712, 2008. https://doi.org/10.1016/j.jweia.2007.06.008

[9] Zhang, A., Gu, M. "Wind tunnel tests and numerical simulations of wind pressures on buildings in staggered arrangement", Journal of Wind Engineering and Industrial Aerodynamics, 96(10-11), pp. 2067-2079, 2008. https://doi.org/10.1016/j.jweia.2008.02.013

[10] Fu, J. Y., Li, Q. S., Wu, J. R., Xiao, Y. Q., Song, L. L. "Field measurements of boundary layer wind characteristics and wind-induced responses of super-tall buildings", Journal of Wind Engineering and Industrial Aerodynamics, 96(8-9), pp. 1332-1358, 2008. https://doi.org/10.1016/j.jweia.2008.03.004

[11] Tse, K. T., Hitchcock, P. A., Kwok, K. C. S., Thepmongkorn, S., Chan, C. M. "Economic perspectives of aerodynamic treatments of square tall buildings", Journal of Wind Engineering and Industrial Aerodynamics, 97(9-10), pp. 455-467, 2009. https://doi.org/10.1016/j.jweia.2009.07.005

[12] Irwin, P. A. "Wind engineering challenges of the new generation of super-tall buildings", Journal of Wind Engineering and Industrial Aerodynamics, 97(7-8), pp. 328-334, 2009. https://doi.org/10.1016/j.jweia.2009.05.001

[13] Tominaga, Y., Stathopoulos, T. "CFD Modelling of Pollution Dis-persion in Building Array: Evaluation of turbulent scalar flux modelling in RANS model using LES results", Journal of Wind Engineering and Industrial Aerodynamics, 104-106, pp. 484-491, 2012. https://doi.org/10.1016/j.jweia.2012.02.004 
[14] Muehleisen, R. T., Patrizi, S. "A new parametric equation for the wind pressure coefficient for low-rise buildings", Energy and Buildings, 57, pp. 245-249, 2013. https://doi.org/10.1016/j.enbuild.2012.10.051

[15] Amin, J. A., Ahuja, A. K. "Effects of Side Ratio on Wind-Induced Pressure Distribution on Rectangular Buildings", Hindawi Publishing Corporation, Journal of Structures, 2013, Article ID: 176739, 2013. https://doi.org/10.1155/2013/176739

[16] Kushal, T., Ahuja, A. K., Chakrabarti, A. "An experimental Investigation of Wind Pressure Developed in Tall Buildings for different plan Shape", International Journal of Innovative Research \& Studies, 1(12), pp. 605-614, 2013.

[17] Verma, S. K., Ahuja, A. K., Pandey, A. D. "Effects of wind incidence angle on wind pressure distribution on square pan tall buildings", Journal of Academic Industrial Research, 1(12), pp. 747-752, 2013.

[18] Chakraborty, S., Dalui, S. K., Ahuja, A. K. "Wind load on irregular plan shaped tall building - a case study", Wind and Structures, 19(1), pp. 59-73, 2014.

https://doi.org/10.12989/was.2014.19.1.059

[19] Chakraborty, S., Dalui, S. K., Ahuja, A. K. "Experimental Investigation of Surface Pressure on '+' Plan Shape Tall Building", Jordan Journal of Civil Engineering, 8(3), pp. 251-262, 2014. [online] Available at: https://jjce.just.edu.jo/issues/show_paper. php?pid $=2750$

[20] Kheyari, P., Dalui, S. K. "Estimation of Wind Load on a Tall Building under Interference Effects: A Case Study", Jordan Journal of Civil Engineering, 9(1), pp. 84-101, 2015. [online] Available at: https://jjce.just.edu.jo/issues/show_paper.php?pid=2884

[21] Paul, R., Dalui, S. K. "Wind effects on 'Z' plan-shaped tall building: a case study", International Journal of Advanced Structural Engineering, 8, pp. 319-335, 2016.

https://doi.org/10.1007/s40091-016-0134-9

[22] Kumar, D., Dalui, S. K. "Effect of internal angles between limbs of cross plan shaped tall building under wind load", Wind and Structures, 24(2), pp. 95-118, 2017. https://doi.org/10.12989/was.2017.24.2.095

[23] Sanyal, P., Dalui, S. K. "Effect of courtyard and opening on a rectangular plan shaped tall building under wind load", International Journal of Advanced Structural Engineering, 10, pp. 169-188, 2018.

https://doi.org/10.1007/s40091-018-0190-4

[24] Bhattacharyya, B., Dalui, S. K. "Investigation of mean wind pressures on 'E' plan shaped tall building", Wind and Structures, 26(2), pp. 99-114, 2018.

https://doi.org/10.12989/was.2018.26.2.099

[25] Elshaer, A., Bitsuamlak, G., El Damatty, A. "Aerodynamic shape optimization for corners of tall buildings using CFD", presented at 14th International Conference on Wind Engineering (ICWE), Porto Alegre, Brazil, June, 21-26, 2015.

[26] Kaveh, A., Abdietehrani, A. "Design of frames using genetic algorithm, force method and graph theory", International Journal for Numerical Methods in Engineering, 61(14), pp. 2555-2565, 2004. https://doi.org/10.1002/nme.1170
[27] Okasha, N. M., Frangopol, D. M. "Lifetime-oriented multi-objective optimization of structural maintenance considering system reliability, redundancy and life-cycle cost using GA", Structural Safety, 31(6), pp. 460-474, 2009.

https://doi.org/10.1016/j.strusafe.2009.06.005

[28] Kaveh, A., Shahrouzi, M. "An Efficient Stochastic Search with Minimal Initial Population for Structural Optimization", Asian Journal of Civil Engineering, 11(6), pp. 741-762, 2010.

[29] Kaveh, A., Kalateh-Ahani, M., Fahimi-Farzam, M. "Constructability optimal design of reinforced concrete retaining walls using a multi-objective genetic algorithm", Structural Engineering and Mechanics, 47(2), pp. 227-245, 2013.

https://doi.org/10.12989/sem.2013.47.2.227

[30] Jalili, S., Hosseinzadeh, Y., Kaveh, A. "Chaotic biogeography algorithm for size and shape optimization of truss structures with frequency constraints", Periodica Polytechnica Civil Engineering, 58(4), pp. 397-422, 2014. https://doi.org/10.3311/PPci.7466

[31] Ezhilsabareesh, K., Rhee, S. H., Samad, A. "Shape optimization of a bidirectional impulse turbine via surrogate models", Engineering Applications of Computational Fluid Mechanics, 12(1), pp. 1-12, 2018.

https://doi.org/10.1080/19942060.2017.1330709

[32] Jeong, H.-S., Kim, K.-Y. "Shape optimization of a feedback-channel fluidic oscillator", Engineering Applications of Computational Fluid Mechanics, 12(1), pp. 169-181, 2018. https://doi.org/10.1080/19942060.2017.1379441

[33] Xie, J. "Aerodynamic optimization in super-tall building designs", presented at The Seventh International Colloquium on Bluff Body Aerodynamics and its Applications (BBAA7), Shanghai, China, Sept. 2-6, 2012.

[34] Elshaer, A., Bitsuamlak, G., El Damatty, A. "Aerodynamic shape optimization of tall buildings using twisting and corner modifications", presented at 8th International Colloquium on Bluff Body Aerodynamics and Applications, Boston, MA, USA, June, 7-11, 2016.

[35] Daemei, A. B., Eghbali, S. R. "Study on aerodynamic shape optimization of tall buildings using architectural modifications in order to reduce wake region", Wind and Structures, 29(2), pp. 139-147, 2019. https://doi.org/10.12989/was.2019.29.2.139

[36] Xin, Q. "Diesel Engine System Design", Woodhead Publishing, Sawston, UK, 2011.

[37] Elshaer, A., Bitsuamlak, G. "Multiobjective Aerodynamic Optimization of Tall Building Openings for Wind-Induced Load Reduction", Journal of Structural Engineering, 144(10), Article number: 04018198, 2018.

[38] Khuri, A. I., Mukhopadhyay, S. "Response surface methodology", WIREs Computational Statistics, 2(2), pp. 128-149, 2010. https://doi.org/10.1002/wics.73

[39] Zhou-Kangas, Y., Miettinen, K. "Decision making in multiobjective optimization problems under uncertainty: balancing between robustness and quality", OR Spectrum, 41, pp. 391-413, 2019. https://doi.org/10.1007/s00291-018-0540-4 
[40] Elshaer, A., Bitsuamlak, G., El Damatty, A. "Enhancing wind performance of tall buildings using corner aerodynamic optimization", Engineering Structures, 136, pp. 133-148, 2017.

https://doi.org/10.1016/j.engstruct.2017.01.019

[41] Revuz, J., Hargreaves, D. M., Owen, J. S. "On the domain size for the steady-state CFD modelling of a tall building", Wind and Structures, 15(4), pp. 313-329, 2012. https://doi.org/10.12989/was.2012.15.4.313

[42] IS "IS 875-3Code of practice for the design loads (Other than Earthquake) for buildings and structures, Part 3: Wind Loads", Bureau of Indian Standards, New Delhi, India, 2015.
[43] Dalui, S. K. "Wind Effects on Tall Buildings with Peculiar Shape", $\mathrm{PhD}$ Thesis, Indian Institute of Technology Delhi, 2008.

[44] ASCE "ASCE/SEI 7-10 Minimum Design Loads for Buildings and Other Structures", American Society of Civil Engineers, Reston, VI, USA, 2010.

[45] AS "AS/NZS 1170.2:2002 Structural Design Actions, Part 2: Wind Actions", Standards Australia, Sydney, NSW, Australia, 2001. 